\title{
Peertechz
}

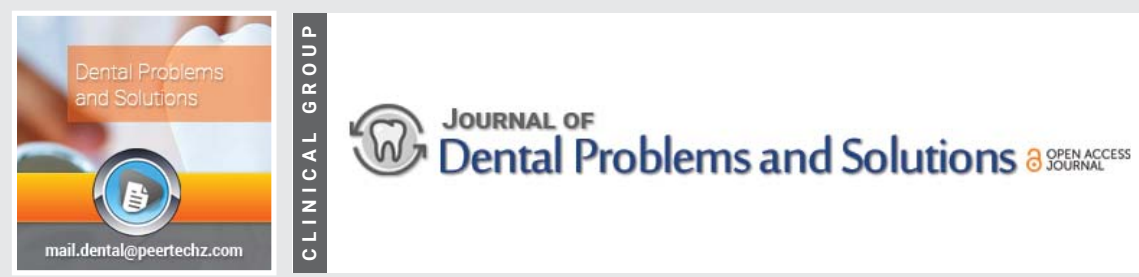

\section{Management of dentoalveolar trauma in adult with nylon splinting and 15 days' delay in treatment-Case report}

\section{Sandra Milena Bornacelly Mendoza*}

General Dentist, Second Year Resident Postgraduate program in Endodontics, University Institution Colleges of Colombia-UNICOC, Colombia
Received: 08 March, 2021

Accepted: 16 March, 2021

Published: 19 March, 2021

*Corresponding author: Sandra Milena Bornacelly Mendoza, General Dentist, Second Year Resident Postgraduate Program in Endodontics, University Institution Colleges of Colombia-UNICOC, Colombia, Tel: +573012805900;

E-mail: sbornacelly@unicoc.edu.co

ORCID: https://orcid.org/0000-0003-3564-7448

Keywords: Dentoalveolar trauma; Splinting teeth; Root fracture; Healing

https://www.peertechzpublications.com

\begin{abstract}
Background and objective: Root fracture is relatively rare and represents only $0.5-7 \%$ of all dental trauma, its incidence is higher in children than in adults and depending on the way it occurs it can be vertical or horizontal, which depends on its location in the case of horizontal fracture, it can be generated at the level of the cervical, middle or apical third of the root, which depends on multiple factors such as the delay in treatment, the type of splint used, age, and fixation time, the healing of the separated fragments may be impaired. Traditionally for the management of root fractures, rigid immobilizations were used for long periods of time, however, currently the management has changed towards the use of more flexible splints such as nylon, orthodontic wires, sutures, among others. The objective of this study is to present the case of a 21-year-old male who suffers a motorcycle accident with multiple trauma injuries including subluxation, root fractures combined with complicated coronal fracture, root fracture with extrusive luxation and individual complicated coronal fracture; splinted with nylon and delayed in treatment for 15 days.
\end{abstract}

Results: it was managed with nylon splinting (fishing line) from tooth 14 to 24 for 25 days with root canal therapy in several teeth; After clinical and radiographic follow-up at 10 weeks, there is evidence of absence of symptoms, return of functionality, different types of segment consolidation despite the delay in treatment and high diastasis of the root fragments.

Conclusion: Early diagnosis with the necessary procedures during trauma management, knowledge of the healing processes and adequate follow-up are key to a correct approach to root fractures.

\section{Abbreviations}

IADT: International Association of Dental Traumatology; TDI: Traumatic Dental Injuries

\section{Introduction}

Traumatic Dental Injuries (TDI) is recognized as a group of injuries affecting the tooth and its supporting structures due to a direct or indirect violent impact [1]. With a low incidence, TDI constitutes up to $5 \%$ of all injuries to the body [2] affecting individuals of all ages; although a higher prevalence is recognized in children than adults, due to the fact that children frequently adopt unpremeditated risk behaviors and their lack of coordination, as well as defects in their occlusion, can favor trauma unlike adults, in which TDI it can be the result of falls, sports activities or accidents; [3] for this reason, the greatest amount of evidence reported focuses on the management of dentoalveolar trauma in children and not in adults [2,3]. This type of injury can vary according to the type, location and direction of the impact, and it is believed that the coronal fracture is the most frequent, representing $65-75 \%$ of all dental trauma, followed by dislocation in $8-20 \%$ of the cases; [4] unlike the root fracture that occurs only in $0.5-7 \%$ of cases, [5] and the fracture can be located at the level of the cervical, middle or apical third of the root, it is characterized by compromising the cement root, dentin, pulp and periodontal ligament; where, generally the apical segment separation does not shift and the coronal segment may or may not shift in various ways $[6,7]$.

In post-impact root fracture, the pulp and other damaged tissues begin the healing process which, it is considered, can be affected by factors such as the patient's age, tooth mobility, the degree of root formation, the location of the fracture, the diastasis of the fragments and time of handling in the 
attention; [7] although, for the latter, some studies support that it is not possible to significantly demonstrate the negative effect of delaying treatment on fracture healing. [8] Since 1967 Andreasen and Hjorting-Hansen classified the consolidation of fragments in this type of fracture as four possible scenarios: scarring with hard tissue, scarring with interposition of only connective tissue, apposition of bone and connective tissue and a fourth scenario with absence of scarring when granulation tissue appears; Any of the first three scenarios is considered favorable, the interposition of granulation tissue being the least favorable because it represents an inflammatory state [9].

Traditionally, root fractures were managed with repositioning of the coronal fragment and immobilization with rigid or semi-rigid splints given that, for years, dental splinting was based on the principles of maxillary fracture whose management is at the expense of rigid splints and for a long time; However, at present this approach has been rethought since the evidence has shown that the use of these can increase the incidence of pulp necrosis and the tendency to external root resorption, so today, to reduce such effects more flexible immobilizations and shorter splinting times are recommended $[8,10]$, with which satisfactory results and a success rate ranging from 54 to $77 \%$ have been reported in root fractures [5]. To be successful, knowledge of all aspects that may or may not be modifiable and affect the results is essential; likewise, the management of all the variables that may affect the prognosis of the treatment at the clinical level, such as the type and time of splinting $[2,7]$.

Dental splints should ideally hold the tooth in position by allowing slightly physiological movements that promote healing, they should be affordable, easy to perform and aesthetically pleasing and stable throughout the fixation period. $[8,11]$ Some of the wires used in orthodontics are considered flexible and have been classified as suitable for splinting in dentoalveolar trauma injuries [1]. The use of nylon (fishing line) has even been reported as a substitute for orthodontic wire in splinting, as this material provides a more aesthetic appearance, is functional, easily acquired, low cost and flexible $[8,10,11]$. It is important to disclose some management guidelines for dentoalveolar trauma injuries that require splinting, because the treatment of these injuries involves a comprehensive approach and requires timely and accurate care [4] from the professional, who has the challenge of restoring dental aesthetics and functionality, positively impacting the health and comfort of those who suffer from it $[2,4]$. The objective of this study is to describe the management of a case of combined dentoalveolar trauma injuries in an adult patient with nylon splinting and treatment delay of 15 days.

\section{Presentation of the case}

We describe the case of a 21-year-old male patient who attended a consultation at the endodontics faculty clinic at the university institution colleges of Colombia in Bogotá for the management of a dentoalveolar trauma that occurred 15 days before the consultation date due to that the patient had multiple coronal fractures referred to the presence of spontaneous pain caused in the upper anterior teeth, as well as in the temporomandibular joint.

No relevant personal systemic history was reported, nor relevant family medical history, the patient only referred hospitalization for 2 days due to the accident with subsequent management at home of antiinflammatory analgesics and antibiotics for 6 days. The extraoral examination revealed the presence of multiple lacerations in the face and neck area, laceration and eversion of the upper lip, pain when opening and closing the right temporomandibular joint with a slight deviation in the shape of an " $\mathrm{s}$ " at the time of closure. The intraoral examination and dental history reveal the clinical findings for teeth reported in Table 1.

Radiographically, in the panoramic and periapical, multiple radiolucent areas are observed at the root level in the middle and apical third of teeth 12,11,21 and 22 compatible with root fracture and radiolucency in the cervical third of the crown of tooth 23 compatible with an apparent coronal fracture. (Figures 1-4) A cold test is performed with Endo-Ice (Coltene) and an increased positive response of 13,12, 22 and 23 is observed, a delayed positive in 11,21; normal positive response in 14 and 24 , pain on palpation in $12,11,21,22$ positive percussion in $13,12,11,21,22$ and 23 with clinical and radiographic findings, diagnoses of dentoalveolar trauma were made per tooth in

\section{Table 1: First visit clinical findings.}

\begin{tabular}{|c|c|}
\hline CLINICAL OSERVATION & TOOTH \\
\hline Bleeding & $13,12,11,21,22,23$ \\
\hline Mobility & $($ III-12,11,21) (I- 13,22,23) \\
\hline Coronal fracture & $12,22,23$ \\
\hline Retained tooth root & 16.26 \\
\hline Coronal restoration & 46 \\
\hline Dental absence & $36,18,38,48$ \\
\hline & \\
\hline & \\
\hline
\end{tabular}

Figure 1: Initial panoramic radiograph.

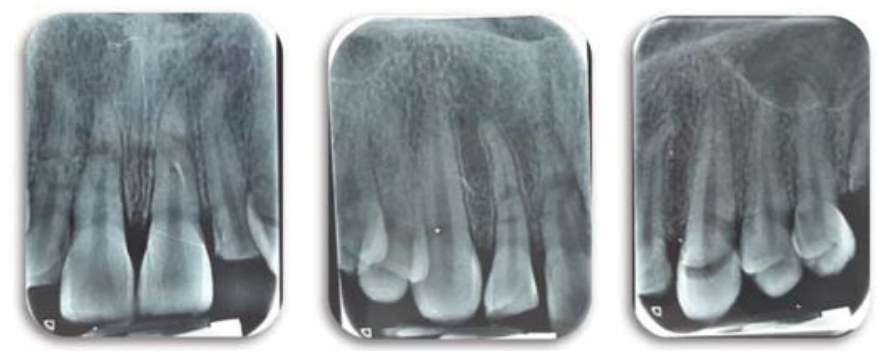

Figures 2-4: Initial periapical radiographs.

Citation: Bornacelly Mendoza SM (2021) Management of dentoalveolar trauma in adult with nylon splinting and 15 days' delay in treatment-Case report. J Dent Probl Solut 8(1): 024-028. DOI: https://dx.doi.org/10.17352/2394-8418.000099 
which some combined injuries are evident (Table 2). The patient is explained everything related to the treatment and flexible splinting with nylon and resin is indicated in the first visit, pertinent consents are signed, in addition the patient also gave his consent and approval for the study of his data and the publication of his case, and immobilization with nylon is carried out, carrying out the following steps: performed dental prophylaxis with a prophylactic brush and hydrogen peroxide, the vestibular surfaces of the anterior teeth were dried, isolation was made with cotton rolls and a mouth opener, it was measured with fishing line from the distal of tooth 14 to the distal area of 24 and was cut approximately $60 \mathrm{~mm}$ nylon (fishing line), the area of the center of the buccal face of teeth $14,13,11,21$ was demineralized with ortho phosphoric acid, and 24 was washed, dried and then tooth by tooth the adhesive was applied with a lamp light-curing for 20 seconds followed by application of resin covering the nylon portion to be fixed on each tooth and point-by-point photopolymerization of resin on each tooth with a lamp photo-cured by 40 seconds, no nylon was fixed in crowns of teeth 22 and 23 , due to the absence of stable coronal remnant to do it, the excess nylon edges of each end were cut and each of the resin points were polished, (see figure 5) Finally, recommendations are given to the patient about avoiding the consumption of hard foods, maintaining good oral hygiene and a control appointment in 15 days.

The patient was called for review 15 days later for clinical and radiographic follow-up, an appointment in which the patient stated that he received a slight accidental impact with the toothbrush on his incisor teeth 11,21 with slight recurrence of pain without causing inflammation in this period. A new control periapical X-ray was taken in which a slight displacement of fragments was evidenced, possibly associated with the blow generated with his toothbrush. (Figure 6) and cold tests are performed again with Endo-Ice, based on the findings found in the diagnostic and radiographic tests, the following pulp diagnoses are found symptomatic irreversible pulpitis in $12,22,23$ indicating root canal therapy root in these teeth due to the pulp exposure they suffered during the fracture, in teeth 11 and 21 a negative response is expressed to tests and evidence of dental color changes indicating a process of pulp necrosis. The patient attends the appointment again at 23 days, cold tests are performed and the findings shown in Table 3 are evident. At this appointment, root canal therapy is performed for the teeth $23,22,21$ and nylon splint is removed. subsequently, the patient does not attend any more appointments until after 45 days, the date on which endodontic therapy is performed on 11.12 .

Table 2: Tooth trauma diagnoses.

\section{DIAGNOSIS}

Horizontal root fracture in the middle third with complicated coronal fracture

Horizontal root fracture in the middle third with extrusive dislocation of the coronal fragment

Horizontal root fracture in the middle third

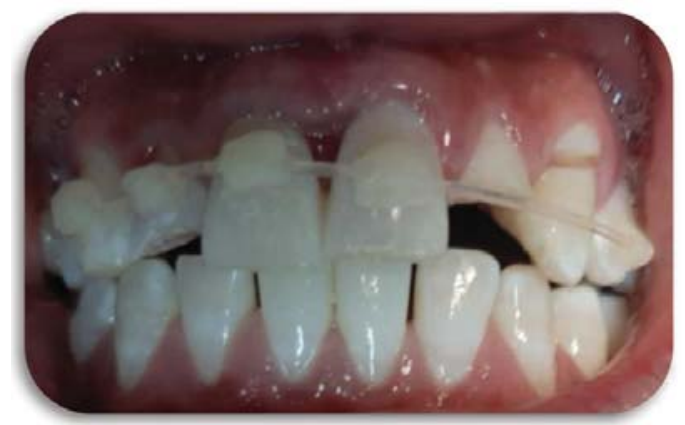

Figure 5: Splinting with nylon first visit.

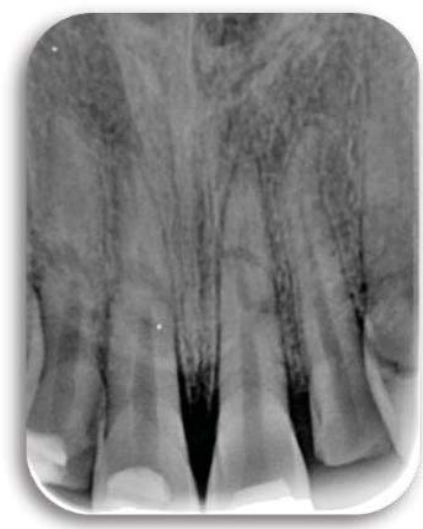

Figure 6: Control radiograph at 15 days.

Table 3: Clinical findings at visit 3 (23 days)

\begin{tabular}{|c|c|}
\hline CLINICAL OSERVATION & TOOTH \\
\hline Mobility & $(\mathrm{I}-11,21)(0-12,13,22,23)$ \\
\hline Cold: + increased & $12,22,23$ \\
\hline Cold: + normal & 13 \\
\hline Cold: Negative & 11,21 \\
\hline
\end{tabular}

\section{Results and discussion}

In the last check-up recorded 10 weeks after their first care, patient satisfaction was evidenced with the improvement in comfort and dental function, as well as the absence of mobility in 13,12,22,23 in teeth 11 and 21 mobility decreased to grade I, radiographically the large displacement of fragments is observed, however there is no interposition of granulation tissue between the parts and the patient is asymptomatic, although the patient has not yet attended their respective appointments for the definitive restoration of affected teeth Evidence of consolidation between fragments is observed because, on radiographic examination, the fragments separated by a radiolucent area are distinguishable and the fractured edges have a rounded appearance that indicates apposition of interproximal bone and connective tissue. Figures 7,8.

The treatment of TDI is based on the type of injury, and the tissue that is affected, if the damage does not involve pulp tissue, it is generally only necessary to do the restoration with clinical and radiographic follow-up as was done in the case of 

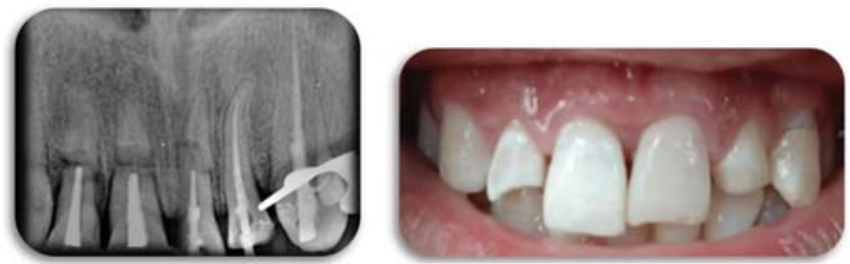

Figure 7,8: X-ray and photo after endodontic therapies.

tooth 13 that had a concussion and has only been under clinical and radiographic control. When pulp involvement is evident, endodontic therapy may be necessary and depending on the type of injury, surgical repositioning and / or stabilization with splints may be necessary [12]. There are several types of splints and the nylon splint (line fishing) is a splint that combines the adhesive technique of composite resin with the use of taut nylon wire 0.6 to 0.7 millimeters in diameter, its has been tested and found to be as flexible as thin stainless steel wire $[8,11]$.

In root fracture, it is essential to relocate the fragments in case of displacement and to maintain a stable splinting, to facilitate its complex repair mechanism [9,12] since 1967 Andreasen and Hjorting-Hansen spoke about the different types of consolidation that can occur in the fractured segments, they state that type I scarring is more commonly found in root fractured teeth in which the coronal fragment is not dislocated or is only slightly dislocated as in tooth 22 of the present case, type II scarring According to these authors, it occurs when there is repair with interproximal connective tissue and on radiographs, the fragments may be separated by radiolucency and the fractured edges have a rounded appearance, as in our case occurred in teeth 11 and 12. It is considered that this type of repair is often after lateral dislocation or extrusion of the coronal fragment as occurred with the with tooth 11 in our case; type III, which is when there is consolidation with interproximal bone and connective tissue that can be radiographically evidenced as the separation of the fragments given by a bone bridge with radiolucency as occurred in tooth 21 and type IV, when there is formation of granulation tissue This occurs because the infected or necrotic pulp tissue causes an inflammatory reaction in the fracture line, which has not been evidenced so far in our case $[9,13]$.

The literature reports that horizontal fracture is more frequent in anterior teeth of young patients and is more frequent in the apical and middle third affected in $57 \%$ and $34 \%$ of the cases respectively; which is evident in our case since all the fractures occurred at the mid and apical level of the roots [6]. It has been considered that horizontal fracture of the middle third has a poor prognosis, due to the difficulty of choosing which fragment should be preserved, in addition to the frequent formation of periodontal pockets [7]. In accordance with Wölner-Hanssen and von Arx T 2010.A horizontal fracture located in the apical third has a better prognosis and can be repaired many times while preserving pulp vitality; generally, it does not present mobility, the tooth is asymptomatic and does not require treatment [14]. In our case, tooth 22 presented a fracture in the apical third but due to the combined injury that additionally had a complicated crown fracture it was necessary to perform endodontic therapy. The literature reports that 10- year survival according to the location of the fracture is $89 \%$ for fractures in the apical third of the root, $78 \%$ when it is located in the middle third, and between $33-67 \%$ in the cervical [15]. The general finding is that apical and radicular fractures have a much higher probability of survival than the estimated survival of cervical fractures $[5-9,15]$.

It is important to consider that in approximately $20-44 \%$ of cases of horizontal root fractures, the pulp becomes necrotic and endodontic therapy is necessary [16]. as happened in the present case in teeth 11 and 21, which at 15 days of evaluation responded negative to the cold test and slight color changes were observed in the crown. In our case, the filling of the canals was carried out to the level of the fracture without joining the apical segments, which coincides with Kocak et al (2008) who affirm that, in most cases, the endodontic treatment of the coronal fragment is sufficient as it is considered that the pulp in the apical fragment is still vital and it is believed that circulation at this level is generally not interrupted [17].

Since 1970, the relationship between the type of scarring and associated factors has been investigated, attributing influence to age, the stage of root development, the location of the fracture, mobility and dislocation of the coronal fragment, as well as the distance between the fragments with stretching or rupture of the pulp tissue at the level of the fracture $[13,15]$. and also the variables dependent on clinical management such as optimal repositioning and the type of splint are associated with a curative response [18]. In terms of time, studies have shown that teeth can be immobilized for only 1 week and be clinically firm so that long splinting times are no longer necessary; however, there may be cases in which the comfort of the patient requires extending the functional splinting for a longer time $[15,18]$ and consequently the latest guidelines of the International Association of Dental Traumatology (IADT) recommend types of splints that are flexible rather than rigid and that are used for less time [19].

Regarding the type of splint, few studies have evaluated the use of nylon as a splinting material, however, it is clear that the recommendation is to use flexible materials; Ben Hassan 2016 in his study compares the Nylon splints with stainless steel, titanium, single and double fiberglass and it has been found that they are just as flexible as those of stainless steel wire, and that it additionally has the advantage of its high aesthetics. It is considered disadvantages that it is difficult to place due to its small diameter and tendency to slip, which could easily break due to movement induced by the fixed tooth but that this can be avoided with greater application of resin [11] and according to Andreassen 2004, age, root development, mobility and dislocation of the coronal fragment and sex are positively related to both pulp healing and repair of the hard tissue of the root fracture [13].

Although it is considered that only after 3 to 6 months, it is possible to make a reliable determination of the type of fracture union $[20,21]$ in our case, favorable indications of fragment consolidation are evidenced at 10 weeks, favorable results are considered for IADT when the patient is asymptomatic, lack of mobility is achieved or that it is slightly increased and that signs of repair of the fragments as met in the present case, which has been managed in accordance with IADT guidelines,

Citation: Bornacelly Mendoza SM (2021) Management of dentoalveolar trauma in adult with nylon splinting and 15 days' delay in treatment-Case report. J Dent 
handling flexible nylon splint for 23 days and it is expected to be able to carry out patient controls according to what is established, which indicates that for root fractures the Clinical and radiographic controls are necessary after 4 weeks, after 6-8 weeks, after 4 months, after 6 months, after 1 year and annually for at least 5 years [19].

It is essential to know their management of root fractures to be able to relocate the fragment in case of displacement and to make good management with stable splinting that favors complex biological repair mechanisms [19,22] Among the available flexible splinting alternatives, nylon seems to be a promising immobilizer material, due to its aesthetics, flexibility and economy that warrant further investigation $[8,11]$.

\section{Conclusion}

Despite the delay in the management of the dentoalveolar trauma in the present case, the evaluation of the healing of the fragments at 10 weeks did not show evidence of granulation tissue formation, and on the contrary, indications of favorable consolidation between the segments were observed. Therefore, it is considered that until then, the results have been favorable and although some studies have supported the idea that the delay in treatment can influence the type of healing after a root fracture, more studies are required to investigate the effect of delay in the treatment of healing in root fractures since in essence the result of healing in these fractures seems to be more related to the stage of root formation, the affectation of the pulp state and the extension of the fracture that with the time of care.

\section{Acknowledgement}

The author is grateful to Dr. Adriana Bornacelly Mendoza for her collaboration so that the present case was published and motivation in the process.

\section{References}

1. Andreasen JO, Lauridsen E, Christensen SS (2009) Development of an interactive dental trauma guide. Pediatric dentistry. 31: 133-136. Link: http://bit.ly/38S4Yt8

2. Zaleckiene V, Peciuliene V, Brukiene V, Drukteinis S (2014) Traumatic denta injuries: etiology, prevalence and possible outcomes. Stomatologija 16: 7-14. Link: http://bit.ly/3qVDvg5

3. Shaikh ZS, Worrall SF (2002) Epidemiology of facial trauma in a sample of patients aged 118 years. Injury. 33: 669-671. Link: http://bit.ly/3vCODIH

4. Serra-Pastor B, Penarrocha-Diago M, Penarrocha-Diago M, Agustín-Panadero R (2016) Treatment and restoration of adult dentoalveolar trauma: A clinical case report. J Clin Exp Dent. 8: e634-e637. Link: http://bit.ly/30RQNQ3

5. Herweijer JA, Torabinejad M, Bakland LK (1992) Healing of horizontal root fractures. J Endod. 18: 118-122. Link: http://bit.ly/3rYZPGR

6. Cvek M, Mejàre I, Andreasen JO (2004) Conservative endodontic treatmen of teeth fractured in the middle or apical part of the root. Dent Traumatol. 20: 261-269. Link: http://bit.ly/3r2W9CF
7. Lo Giudice R, Lizio A, Cervino G, Fabiana N, Francesco P,et al. (2018) The Horizontal Root Fractures. Diagnosis, Clinical Management and Three-Year Follow-Up. Open Dent J. 12: 687-695. Link: http://bit.ly/3tyCj3W

8. Kahler B, Hu JY, Marriot-Smith CS, Heithersay GS (2016) Splinting of teeth following trauma: a review and a new slinting recommendation. Aust Dent $\mathrm{J}$. 61: 59-73. Link: http://bit.ly/38TbRKz

9. Andreasen JO, Hjorting-Hansen E (1967) Intraalveolar root fractures: radiographic and histologic study of 50 cases. J Oral Surg: 25: 414-426. Link: http://bit.ly/3eSA1J6

10. Welbury R, Kinirons MJ, Day P, Humphreys K, Gregg TA (2002) Outcomes for rootfractured permanent incisors: a retrospective study. Pediatr Dent. 24: 98 102. Link: http://bit.ly/2QiUM6r

11. Ben Hassan MW, Andersson L, Lucas PW (2016) Stiffness characteristics of splints for fixation of traumatized teeth. Dent Traumatol. 32: 140-145. Link: http://bit.ly/3cJabVd

12. Reddy LV, Bhattacharjee R, Misch E, Sokoya M, Ducic Y (2019) Dental Injuries and Management. Facial Plast Surg. 35: 607-613. Link: http://bit.ly/3eRv0jZ

13. Andreasen JO, Andreasen FM, Mejàre I, Cvek M (2004) Healing of 400 intraalveolar root fractures. 2. Effect of treatment factors such as treatment delay, repositioning, splinting type and period and antibiotics. Dent Traumatol. 20: 203-211. Link: http://bit.ly/3cKz5DJ

14. Wölner-Hanssen AB, Von Arx T (2010) Permanent teeth with horizontal root fractures after dental trauma. A retrospective study. Schweiz Monatssch Zahnmed. 120: 200-212. Link: http://bit.ly/3cQ9FVw

15. Andreasen JO, Ahrensburg SS, Tsilingaridis G (2012) Root fractures: the influence of type of healing and location of fracture on tooth survival rates - an analysis of 492 cases. Dent Traumatol. 28: 404-409. Link: http://bit.ly/3r06Cz1

16. Kallel I, Douki N, Amaidi S, Ben Amor F (2020) The Incidence of Complications of Dental Trauma and Associated Factors: A Retrospective Study. Int J Dent. 2968174. Link: http://bit.ly/3tv7sFy

17. Kocak S, Cinar S, Kocak MM, Kayaoglu G (2008) Intraradicular splinting with endodontic instrument of horizontal root fracture--case report. Dent Traumatol. 24: 578-580. Link: http://bit.ly/3eOLWHP

18. Heithersay GS, Kahler B (2013) Healing responses following transverse root fracture: a historical review and case reports showing healing with (a) calcified tissue and (b) dense fibrous connective tissue. Dent Traumatol. 29: 253-265. Link: http://bit.ly/3ls3Ukq

19. Bourguignon $C$, Cohenca N, Lauridsen $E$, Flores $M T$, O'Connell $A C$, et al. (2020) International Association of Dental Traumatology guidelines for the management of traumatic dental injuries: 1 . Fractures and luxations. Dent Traumatol. 36: 314-330. Link: http://bit.ly/3txqX0

20. Cvek M, Andreasen JO, Borum MK (2001) Healing of 208 intra-alveolar root fractures in patients aged 7-17 years. Dent Traumatol. 17: 53-62. Link: http://bit.ly/3eZPd6W

21. Soares Ditzel A, Tulio Manfron AP, Westphalen $F H$, da Silva Neto UX Kowalczuck A, et al. (2018) Management of Multiple Dental Trauma: Case Report with Eight-Year Followup. Iran Endod J. 13: 410-412. Link: http://bit.ly/3bYjlhq

22. Andreasen FM, Andreasen JO, Bayer T (1989) Prognosis of root-fractured permanent incisors--prediction of healing modalities. Endod Dent Traumatol. 5: 11-22. Link: http://bit.ly/3eWlzj5 